\title{
Correlation of Expression of Tenascin C and Blood Vessel Density in Non-small Cell Lung Cancers
}

\author{
ADAM RZECHONEK ${ }^{1}$, JEDRZEJ GRZEGRZOLKA ${ }^{2}$, PIOTR BLASIAK ${ }^{1}$, MACIEJ ORNAT $^{2}$, \\ ALEKSANDRA PIOTROWSKA ${ }^{2}$, ALEKSANDRA NOWAK $^{2}$ and PIOTR DZIEGIEL ${ }^{2,3}$ \\ ${ }^{1}$ Department and Clinic of Thoracic Surgery and ${ }^{2}$ Department of Human Morphology and Embryology, \\ Division of Histology and Embryology, Wroclaw Medical University, Wroclaw, Poland; \\ ${ }^{3}$ Department of Physiotherapy, University School of Physical Education, Wroclaw, Poland
}

\begin{abstract}
Background/Aim: Non-small cell lung cancers are cancer diseases that rank second in terms of incidence and first in terms of mortality, worldwide. Stromal cells of these cancers express tenascin C (TNC) - hexameric glycoprotein, which is also expressed during foetal life. TNC is also observed in stromal cells of most human cancers. In some cancers, TNC was shown to influence proliferation and migration of cancer cells and angiogenesis. The aim of this work was to analyze the correlation of expression of TNC with the markers of vascular endothelial cells, CD31 and CD34, and clinicopathological data in NSCLC. Materials and Methods: Archival paraffin blocks from 101 cases of NSCLC were used for the studies. Immunohistochemical reactions were carried out on paraffin sections using mouse monoclonal antibodies anti-TNC, anti-CD31 and anti-CD34, with the use of Autosteiner Link-48. Results: Statistical analysis of the results showed positive correlation between TNC expression and $C D 31(+)$ and CD34(+) microvessel density $(M V D)(r=0.456$, $p<0.0001 ; r=0.296, p<0.01$, respectively). Conclusion: Based on the obtained results it can be concluded, that TNC may be involved in angiogenesis in NSCLC.
\end{abstract}

Lung cancer is the most common cause of death and the second cancer disease in terms of incidence in the world. Despite graduate, small improvements in lung cancer therapy over the last decades (from $14.3 \%$ to $18.4 \%$ 5-year survival), it is still a very important clinical problem (1-3).

Taking into account histological structure, course of the disease and the type of therapy used, lung cancers are classified

Correspondence to: Dr. Adam Rzechonek, Department of Thoracic Surgery, Wroclaw Medical University, Grabiszynska 105, 53-439 Wroclaw, Poland. Tel: +48 71 3349539,e-mail: adam.rzechonek@ gmail.com

Key Words: Tenascin C, TNC, CD31, CD34, angiogenesis, NSCLC. as small-cell and non-small cell lung cancers (NSCLC). Among the latter, one can distinguish 3 basic histological subtypes: squamous cell carcinoma, adenocarcinoma and large cell carcinoma, which account for over $90 \%$ of all diagnosed cases of non-small cell cancers (4). The most common subtype of lung cancer among women is adenocarcinoma, whereas in men - squamous cell carcinoma (5-7).

Tenascin C (TNC) is an extracellular matrix hexameric glycoprotein. In the human body, it is expressed during foetal life, and plays a role in the development of cardiac muscle, valves and coronary vasculature. During foetal life, tenascin is found in large amounts in extensively migrating cells, inter alia in neural tube cells, as well as in tendinous, bone and chondroid tissue $(8,9)$. In the adult human body, tenascin is not present and can be found in small amounts only in inflammations and during wound healing. It can also be found in pathological conditions in various types of cancers $(10,11)$. Tenascin structure contains domains that interact $e . g$. with elements of Wnt and RhoA pathways or with components of the extracellular matrix (e.g. fibronectin, integrin) (10-11). In some tumours, TNC may stimulate proliferation and migration of cancer cells. Additionally, tenascin can affect angiogenesis process. Angiogenesis is a process of new blood vessels formation by expansion of already existing vasculature (12). CD31 is a marker of endothelial cells from existing blood vessels, whereas CD34 expression is characteristic of newly formed vasculature (12).

Increased expression of TNC was observed in a large number of malignant neoplasms, such as e.g. glioblastoma multiforme, osteosarcoma, chondrosarcoma, bladder cancer, pancreatic carcinoma, NSCLC and ductal breast carcinoma (13-20). In case of bladder cancer, it was shown, that high TNC expression in extracellular matrix was associated with significantly shorter patients' survival time, whereas expression of TNC in the cytoplasm of cancer cells was associated with longer survival (21). In glioma, higher TNC expression was correlated with an increased ability for migration and 
proliferation of neoplastic cells (22). In pancreatic cancer, TNC can reduce cellular adhesion and thus increase the ability of cancer cells for migration and metastasis $(16,19)$. In ductal breast cancer, increased TNC expression was correlated with the expression of fibroblast growth factor (FGF) and vimentin. TNC overexpression in the same types of cancer was associated e.g. with the presence of metastases into lymph nodes, shorter survival time, increased expression of Ki-67 as well as lack of expression of estrogen receptor (18).

It is also suggested, that TNC affects angiogenesis. In an in vitro model, subjecting glioblastoma multiforme cells to TNC resulted in an increased synthesis of proangiogenic factors (23). On the other hand, lung cancer and clear cell renal cell carcinoma showed high TNC expression adjacent to vascular endothelial cells CD31(+) $(24,25)$. In NSCLC, increased TNC was correlated with tumour size and the presence of lymph node metastases (26). Moreover, intensified TNC expression in this type of cancer was shown in patients with recurrent disease (26).

The aim of this study was to analyze TNC expression in correlation with microvascular density (MVD) CD31(+) and CD34(+), and clinicopathological data.

\section{Materials and Methods}

An immunohistochemical (IHC) study was performed on 101 paraffin blocks obtained from patients diagnosed with NSCLC and treated between years 1998-2010 in the Department and Clinic of Thoracic Surgery of Wroclaw Medical University, Poland. All patients were treated surgically, and tissue specimens were prepared prior to chemotherapy. Patients from the IHC group were followed up for $31.53 \pm 41.18$ (median: 14.0 ; range=1-145 months) months. In this period 73 patients died. The experiment was performed in accordance to ethical standards and was approved by the Ethics Committee of Wroclaw Medical University (decision no. KB 83/2011). Patients' demographic and clinicopathological characteristics are presented in Table I.

Immunohistochemistry (IHC). All reactions were performed on 4- $\mu$ mthick paraffin sections. In order to examine the expression of TNC, CD31 and CD34, the protocol using Dako Autostainer Link48 (Dako, Glostrup, Denmark) was introduced. Deparaffinization, rehydration and antigen retrieval were conducted by boiling in EnVision FLEX Target Retrieval Solution ( $\mathrm{pH}=9,20 \mathrm{~min}, 97^{\circ} \mathrm{C}$; Dako, Glostrup, Denmark) using the Pre-Treatment Link platform (Dako, Glostrup, Denmark). Activity of endogenous peroxidase was blocked by $5 \mathrm{~min}$ incubation in EnVision FLEX Peroxidase-Blocking Reagent (Dako, Glostrup, Denmark). Sections were incubated with the primary mouse monoclonal antibody for anti-human TNC (Leica Novocastra, Nussloch, Germany), diluted 1:50, CD31 antibody (ready-to-use, IR610, Dako, Glostrup, Denmark), CD34 (ready-to-use, IR632, Dako, Glostrup, Denmark) for $20 \mathrm{~min}$ at room temperature (RT). Following this EnVision FLEX/HRP - secondary antibodies were applied (20 min at RT; Dako, Glostrup, Denmark). Diaminobenzidine (DAB, Dako, Glostrup, Denmark) was used as the peroxidase substrate and the sections were incubated for $10 \mathrm{~min}$ at RT. All slides were counterstained with EnVision FLEX Hematoxylin (Dako, Glostrup,
Table I. Characteristics of patients and tumours.

\begin{tabular}{|c|c|c|}
\hline & \multicolumn{2}{|c|}{ IHC $(n=101)$} \\
\hline Mean age (range & \multicolumn{2}{|c|}{$62.86 \pm 8.862(39-87)$} \\
\hline Parameters & $\mathrm{N}$ & $\%$ \\
\hline \multicolumn{3}{|l|}{ Gender } \\
\hline Male & 80 & 79.21 \\
\hline Female & 21 & 20.79 \\
\hline \multicolumn{3}{|l|}{ Tumour size } \\
\hline $\mathrm{T} 1$ & 25 & 24.75 \\
\hline $\mathrm{T} 2$ & 52 & 50.50 \\
\hline $\mathrm{T} 3$ & 10 & 8.91 \\
\hline $\mathrm{T} 4$ & 16 & 15.84 \\
\hline \multicolumn{3}{|l|}{ Lymph nodes } \\
\hline No & 48 & 47.52 \\
\hline $\mathrm{N} 1, \mathrm{~N} 2, \mathrm{~N} 3$ & 53 & 52.48 \\
\hline \multicolumn{3}{|l|}{ Grade } \\
\hline G1 & 8 & 7.92 \\
\hline $\mathrm{G} 2$ & 58 & 57.43 \\
\hline G3 & 26 & 25.74 \\
\hline No data & 9 & 8.91 \\
\hline \multicolumn{3}{|l|}{ pTNM } \\
\hline I & 41 & 40.59 \\
\hline II & 16 & 15.84 \\
\hline III & 41 & 40.59 \\
\hline IV & 3 & 2.97 \\
\hline \multicolumn{3}{|l|}{ Stage } \\
\hline Early & 57 & 56.44 \\
\hline Advanced & 45 & 43.56 \\
\hline \multicolumn{3}{|l|}{ Tenascin C } \\
\hline 0 & 18 & 17.82 \\
\hline $1-12$ & 83 & 82.18 \\
\hline \multicolumn{3}{|l|}{$\mathrm{CD} 31$} \\
\hline$\leq$ median $(8.33$ & 52 & 51.49 \\
\hline >median $(8.33$ & 49 & 48.51 \\
\hline \multicolumn{3}{|l|}{ CD34 } \\
\hline$\leq$ median $(9.33$ & 52 & 51.49 \\
\hline >median $(9.33$ & 49 & 48.51 \\
\hline
\end{tabular}

IHC: Immunohistochemistry; n: number of cases.

Denmark). Subsequently, the preparations were mounted in Mounting Medium (Dako, Glostrup, Denmark).

Evaluation of IHC reactions. All sections were evaluated using a BX-41 light microscope (Olympus, Tokyo, Japan) by two pathologists who were blinded to the patients' clinical data. In doubtful cases, a re-evaluation with a double-headed microscope was performed until a consensus was achieved. CD31 expression was observed in a cytoplasm of endothelial cells. Initially, whole slide was analysed as follows: the sections were first scanned at low power $(\times 40$ and $\times 100$ magnification) to identify the hot-spots (areas of potentially highest microvessel density (MVD) count). Subsequently, these areas were examined under $\times 200$ magnification using a Chalkley Point Array graticule (Pyser Sgi., Edenbridge, UK). The Chalkley count was regarded as the number of grid points that hit stained vessels. An average score was determined for three 


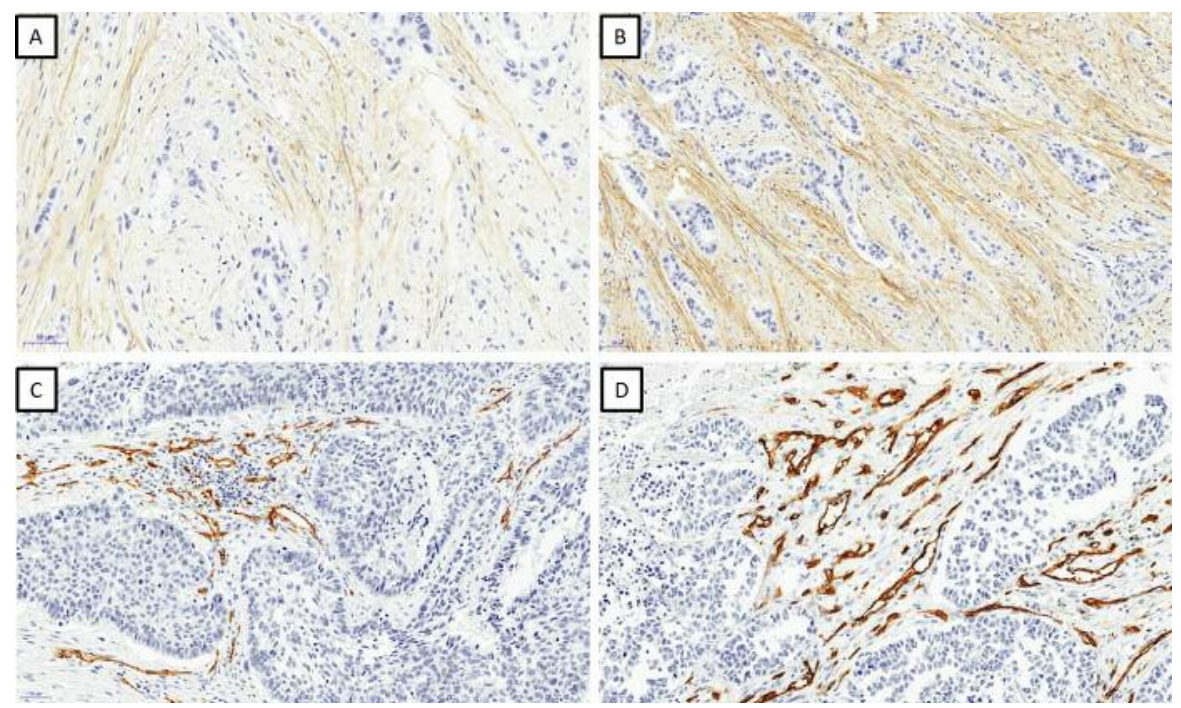

Figure 1. Low (A) and high (B) expression of tenascin C in stromal cells of non-small cell lung cancer (NSCLC) and expression of CD31 (C) and CD34 (D) in vascular endothelium in NSCLC (Magnification $\times 200$ ).

hot-spots. The evaluation of tenascin-C reaction intensities was appraised using the 12-point immunoreactive score (IRS) of Remmele and Stegner, in which the percentage of positive cells and the intensity of the reaction were taken into account (27). The final score assigned was the multiplicative product of these two parameters (Table II).

Statistical analysis. Shapiro-Wilk test was used for evaluating the normality assumption of the examined groups. For comparing the differences in the expression of examined markers in all groups of patients' pairs and clinical-pathological data, the Mann-Whitney test was used. Additionally, the Spearman correlation test was used to analyse the existing correlations. The Kaplan-Meyer method was used to construct survival curves. To evaluate the analysis of survival, Mantel-Cox test was performed. All statistical analyses were performer using Prism 5.0 (GraphPad, La Jolla, CA, USA). The results were considered as statistically significant when $p<0.05$.

\section{Results}

Based on the conducted experiments, cytoplasmic TNC expression in stromal cells was shown in $82.17 \%$ of analyzed cases (Figure 1A and B). Statistical analysis of the obtained results did not show any differences between histological subtypes of NSCLC: squamous cell carcinoma, adenocarcinoma and large cell carcinoma. Evaluation of TNC expression and clinical-pathological data of NSCLC patients revealed a statistically significantly higher expression in $\mathrm{G} 2$ tumours in comparison to $\mathrm{G} 1$, and $\mathrm{TNC}$ expression higher in $\mathrm{G} 3$ in comparison to G1 (Figure 2A).

Density analysis of CD31-positive (CD31(+)) blood vessels showed that they were present in $93.06 \%$, and CD34-positive
Table II. The immunoreactive (IRS) score was used to evaluate cytoplasmic expression of tenascin $C(T N C)$. The final score is multiplication of percentage of positive cells $(A)$ and the intensity of colour reaction $(B)$.

\begin{tabular}{ll}
\hline Percentage of positive cells & Intensity of colour reaction \\
\hline $0 \mathrm{pts}-0 \%$ cells & $0 \mathrm{pts}-$ no staining \\
$1 \mathrm{pt}-1 \%-10 \%$ cells & $1 \mathrm{pt}-$ low \\
$2 \mathrm{pts}-11 \%-50 \%$ cells & $2 \mathrm{pts}-$ moderate \\
$3 \mathrm{pts}-51 \%-80 \%$ cells & $3 \mathrm{pts}-$ intense \\
$4 \mathrm{pts}->80 \%$ cells &
\end{tabular}

pt: Point; pts: points

(CD34(+)) were present in 95.04\% of cases (Figure 1C and 1D). No statistically significant differences were observed in the case of CD34(+) blood vessel density analysis and the following features: G, pT, stage, sex or patient survival.

The expression correlation analysis showed a medium positive correlation between TNC expression and the density of CD31(+) vasculature $(\mathrm{r}=0.456, p<0.0001)$ (Figure $2 \mathrm{~B})$, as well as a weak positive correlation between TNC expression and the density of CD34(+) blood vessels $(\mathrm{r}=0.296, p<0.01)$ (Figure 2C).

\section{Discussion}

The increased TNC expression in cancer and stromal cells of various cancer types has been described on many occasions (11, 13-20). In our studies, we observed an increased TNC expression 


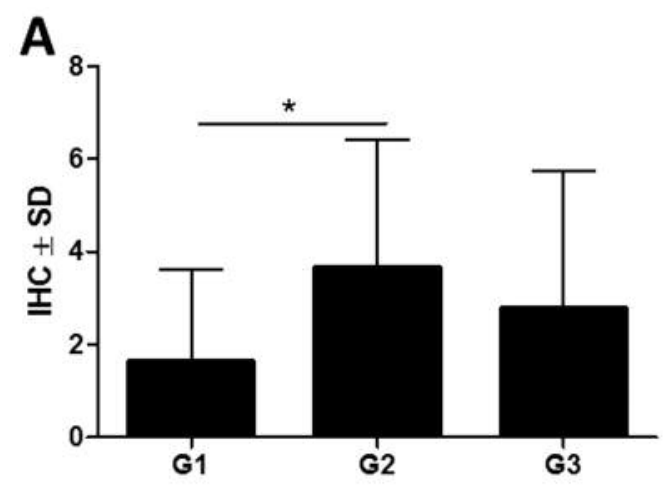

B
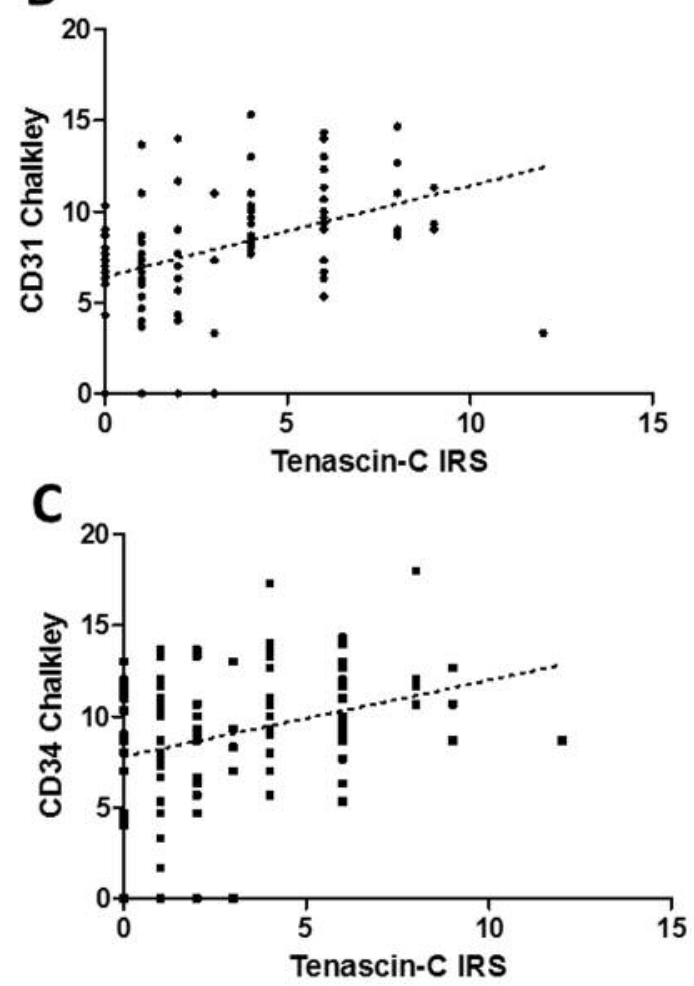

Figure 2. There is a higher expression of tenascin $C$ in cases with a $G 2$ grade in comparison to $G 1$, and an upward trend in $G 3$ in comparison to $G 1$ (A). Positive correlation between tenascin $C$ expression and microvessel density (MVD) CD31(+) (B) and MVD CD34(+) (C) $\left(r=0.456 ; p<0.0001\right.$ and $r=0.296 ; p<0.01$, respectively). ${ }^{*} p<0.05$.

in stromal cells in cases of higher histological malignancy, which may prove involvement of TNC in cancer progression.

We observed positive correlation between TNC expression and the density of $\mathrm{CD} 31(+)$ and $\mathrm{CD} 34(+)$ blood vessels. So far, correlation between TNC expression and angiogenesis in NSCLC has been poorly understood (24). In the analysed literature, an attempt was made to evaluate only correlation between angiogenesis in NSCLC and plasma TNC concentration, but not TNC expression in stromal cells of $\operatorname{NSCLC}(17,24)$. TNC involvement in angiogenesis is supported also by the synthesis of proangiogenic factors by glioblastoma multiforme cells treated with TNC, as well as TNC expression in the stroma of NSCLC and clear cell renal cell carcinoma adjacent to CD31-expressing blood vessels $(23,25,28)$. On the other hand, other authors observed also positive correlation between TNC expression and vasculature density in prostate cancer (29).

The above data show that TNC expression may play different roles in the progression of various human cancer types. In lung cancer, TNC degradation may be an additional factor affecting tenascin expression in stromal cells, but this will require further confirmatory analysis (30). Based on the obtained results, it seems that TNC is probably engaged in the mechanism of cancer angiogenesis in NSCLC.

\section{References}

1 Wang S, Sun T, Sun H, Li X, Li J, Zheng X, Mallampati S, Sun H, Zhou X, Zhou C, Zhang H, Cheng Z and Ma H: Survival improvement in patients with non-small cell lung cancer between 1983 and 2012: Analysis of the surveillance, epidemiology, and end results database. Tumour Biol 39(5): 1010428317691677, 2017.

2 Zappa C and Mousa S: Non-small cell lung cancer: current treatment and future advances. Transl Lung Cancer Res 5: 288300, 2016.

3 Kosacka M and Jankowska R: The epidemiology of lung cancer. Pneumonol Alergol Pol 75: 76-80, 2007.

4 Ferlay J, Soerjomataram I, Dikshit R, Eser S, Mathers C, Rebelo M, Parkin DM, Forman D and Bray F: Cancer Incidence and Mortality Worldwide sources, methods and major patterns in GLOBOCAN 2012. Int J Cancer 136: E359-386, 2015.

5 De Matteis S, Consonni D, Pesatori AC, Bergen AW, Bertazzi PA, Caporaso NE, Lubin JH, Wacholder S and Landi MT: Are Women Who Smoke at Higher Risk for Lung Cancer Than Men Who Smoke? Am J Epidemiol 177: 601-612, 2013.

6 Meza R, Meernik C, Jeon J and Cote ML: Lung cancer incidence trends by gender, race and histology in the United States, 1973-2010. PLoS One 10: e0121323, 2015.

7 Kiyohara $\mathrm{Cx}$ and Ohno Y: Sex differences in lung cancer susceptibility: a review. Gend Med 7: 381-401, 2010.

8 Midwood KS, Hussenet T, Langlois B and Orend G: Advances in tenascin-C biology. Cell Mol Life Sci 68: 3175-3199, 2011.

9 Chiquet-Ehrismann R, Orend G, Chiquet M, Tucker RP and Midwood KS: Tenascins in stem cell niches. Matrix Biol 37: 112-123, 2014.

10 Parekh K1, Ramachandran S, Cooper J, Bigner D, Patterson A and Mohanakumar T: Tenascin-C, over expressed in lung cancer down regulates effector functions of tumor infiltrating lymphocytes. Lung Cancer 47: 17-29, 2005.

11 Orend G: Potential oncogenic action of tenascin-C in tumorigenesis. Int J Biochem Cell Biol 37: 1066-1083, 2005.

12 Nowak A, Grzegrzolka J, Paprocka M, Piotrowska A, Rys J, Matkowski R, and Dziegiel P: Nestin-positive microvessel density is an independent prognostic factor in breast cancer. Int J Oncol 51: 668-676, 2017. 
13 Mazur MR and Kopczyńska E: Potencjalne zastosowanie tenascyny $\mathrm{C}$ w diagnozowaniu i leczeniu nowotworów. Nowotw J Oncol 63: 463-475, 2013.

14 Tanaka M, Yamazaki T, Araki N, Yoshikawa H, Yoshida T, Sakakura $\mathrm{T}$ and Uchida A: Clinical significance of tenascin- $\mathrm{C}$ expression in osteosarcoma: tenascin-C promotes distant metastases of osteosarcoma. Int J Mol Med 5: 505-510, 2000.

15 Ghert MA, Jung ST, Qi W, Harrelson JM, Erickson HP, Block JA and Scully SP: The clinical significance of tenascin-C splice variant expression in chondrosarcoma. Oncology 61: 306-314, 2001

16 Chen J, Chen Z, Chen M, Li D, Li Z, Xiong Y, Dong J and Li $\mathrm{X}$ : Role of fibrillar Tenascin-C in metastatic pancreatic cancer. Int J Oncol 34: 1029-1036, 2009.

17 Gebauer F, Gelis S, Zander H, Meyer KF, Wolters-Eisfeld G, Izbicki JR, Bockhorn $\mathrm{M}$ and Tachezy $\mathrm{M}$ : Tenascin-C serum levels and its prognostic power in non-small cell lung cancer. Oncotarget 7: 20945-20952, 2016.

18 Yang Z, Ni W, Cui C, Fang L and Xuan Y: Tenascin C is a prognostic determinant and potential cancer-associated fibroblasts marker for breast ductal carcinoma. Exp Mol Pathol 102: 262-267, 2017.

19 Midwood KS and Orend G: The role of tenascin-C in tissue injury and tumorigenesis. J Cell Commun Signal 3: 287-310, 2009.

20 Jones PL and Jones FS: Tenascin-C in development and disease: gene regulation and cell function. Matrix Biol 19: 581-596, 2000

21 Brunner A, Mayerl C, Tzankov A, Verdorfer I, Tschörner I, Rogatsch $\mathrm{H}$ and Mikuz G: Prognostic significance of tenascin$\mathrm{C}$ expression in superficial and invasive bladder cancer. J Clin Pathol 57: 927-931, 2004.

22 Herold-Mende C, Mueller MM, Bonsanto MM, Schmitt HP, Kunze S and Steiner HH: Clinical impact and functional aspects of tenascin-C expression during glioma progression. Int J Cancer 98: 362-269, 2002.

23 Rupp T, Langlois B, Koczorowska MM, Radwanska A, Sun Z, Hussenet T, Lefebvre O, Murdamoothoo D, Arnold C, Klein A, Biniossek ML, Hyenne V, Naudin E, Velazquez-Quesada I, Schilling O, Van Obberghen-Schilling E and Orend G: Tenascin$\mathrm{C}$ orchestrates glioblastoma angiogenesis by modulation of proand anti-angiogenic signaling. Cell Rep 17: 2607-2619, 2016.
24 Ishiwata T, Takahashi K, Shimanuki Y, Ohashi R, Cui R, Takahashi F, Shimizu K, Miura K and Fukuchi Y: Serum tenascin- $\mathrm{C}$ as a potential predictive marker of angiogenesis in non-small cell lung cancer. Anticancer Res 25: 489-495, 2005.

25 Galler K, Junker K, Franz M, Hentschel J, Richter P, Gajda M, Göhlert A, von Eggeling F, Heller R, Giavazzi R, Neri D, Kosmehl H, Wunderlich $\mathrm{H}$ and Berndt A: Differential vascular expression and regulation of oncofetal tenascin-C and fibronectin variants in renal cell carcinoma (RCC): implications for an individualized angiogenesis-related targeted drug delivery. Histochem Cell Biol 137: 195-204, 2012.

26 Cai M, Xie ZT, Weng Y, Chang Q and Chang JH: Correlation of tenascin-C degradation fragment with recurrence and/or metastasis in early non-small-cell lung cancer. Zhonghua Zhong Liu Za Zhi 29: 518-521, 2007.

27 Remmele W and Stegner HE: Recommendation for uniformdefinition of nimmunoreactive Score (IRS) for immunohistochemicalestrogenreceptor detection (ER-ICA) in breast cancer. Pathologe 8: 138-140, 1987.

28 Cai M, Onoda K and Takao M: Degradation of Tenascin-C and Activity of Matrix Metalloproteinase-2 Are Associated with Tumor Recurrence in Early Stage Non-Small Cell Lung Cancer. Clin Cancer Res 8: 1152-1156, 2002.

29 Ni WD, Yang ZT, Cui CA, Cui Y, Fang LY and Xuan YH: Tenascin-C is a potential cancer-associated fibroblasts marker and predicts poor prognosis in prostate cancer. Biochem Biophys Res Commun 486: 607-612, 2017.
Received February 12, 2018

Revised March 4, 2018

Accepted March 5, 2018 